\title{
Review of Acute Traumatic Closed Mallet Finger Injuries in Adults
}

\author{
Santiago Salazar Botero ${ }^{1}$, Juan Jose Hidalgo Diaz ${ }^{1}$, Anissa Benaïda ${ }^{2}$, Sylvie Collon ${ }^{3}$, \\ Sybille Facca ${ }^{1}$, Philippe André Liverneaux ${ }^{1}$ \\ ${ }^{1}$ Department of Hand Surgery, SOS main, CCOM, University Hospital of Strasbourg, FMTS, University of Strasbourg, Illkirch, France; \\ ${ }^{2}$ Department of Orthopaedics, CHU Blida, Saad Dahleb University, Blida, Algeria; ${ }^{3}$ Department of Orthopaedic Surgery, Caen University \\ Hospital, Caen, France
}

In adults, mallet finger is a traumatic zone I lesion of the extensor tendon with either tendon rupture or bony avulsion at the base of the distal phalanx. High-energy mechanisms of injury generally occur in young men, whereas lower energy mechanisms are observed in elderly women. The mechanism of injury is an axial load applied to a straight digit tip, which is then followed by passive extreme distal interphalangeal joint (DIPJ) hyperextension or hyperflexion. Mallet finger is diagnosed clinically, but an X-ray should always be performed. Tubiana's classification takes into account the size of the bony articular fragment and DIPJ subluxation. We propose to stage subluxated fractures as stage III if the subluxation is reducible with a splint and as stage IV if not. Left untreated, mallet finger becomes chronic and leads to a swan-neck deformity and DIPJ osteoarthritis. The goal of treatment is to restore active DIPJ extension. The results of a six- to eight-week conservative course of treatment with a DIPJ splint in slight hyperextension for tendon lesions or straight for bony avulsions depends on patient compliance. Surgical treatments vary in terms of the approach, the reduction technique, and the means of fixation. The risks involved are stiffness, septic arthritis, and osteoarthritis. Given the lack of consensus regarding indications for treatment, we propose to treat all cases of mallet finger with a dorsal glued splint except for stage IV mallet finger, which we treat with extra-articular pinning.

Keywords Mallet finger / Mallet fracture / Bony mallet

\author{
Correspondence: Philippe André \\ Liverneaux \\ Department of Hand Surgery, \\ University Hospital of Strasbourg, \\ 10 avenue Baumann, 67403 IIIkirch, \\ France \\ Tel: $+33-6-8889-4779$ \\ Fax: +33-3-8855-2363 \\ E-mail: Philippe.liverneaux@chru- \\ strasbourg.fr
}

Received: 9 Jan $2016 \bullet$ Revised: 23 Feb $2016 \bullet$ Accepted: 24 Feb 2016

pISSN: 2234-6163 • elSSN: 2234-6171 • http://dx.doi.org/10.5999/aps.2016.43.2.134• Arch Plast Surg 2016;43:134-144

\begin{abstract}
Philippe Liverneaux has conflict of interest with Newclip Technics and Argomedical. None of the other authors has conflit of interest.
\end{abstract}

\section{INTRODUCTION}

\section{Definition}

Mallet finger in adults is a traumatic lesion of the terminal extensor band in zone 1 , and is characterized by intact skin and division of the tendon insertion alone (tendinous mallet) or an avulsion of less than one third of the articular surface of the distal phalanx (bony mallet) [1-3]. The expression "mallet finger" is inaccurate because the deformity is reducible in its acute phase [4]. Some prefer the expression "drop finger," which provides a better description of the consequences of the lesion [5], or the expression "baseball finger," which describes the mechanism of injury $[6,7]$. A mallet finger lesion can be considered a mirror lesion to an avulsion of the distal flexor profundus, also known 
as a "jersey finger" or a "rugby finger." Some authors extend the definition of mallet finger to other zone 1 divisions of the extensor, including skin wounds (open mallet) [8] and/or fractures of the distal phalanx involving more than one third of the articular surface $[9,10]$ or displaced fractures of the distal phalanx growth plate (Seymour lesions) [11]. In this article, we only consider acute closed lesions in adults.

\section{Historical background}

Segond described the first bony mallet finger in 1880 and Shoening the first tendinous mallet finger in 1887 [12]. The initial treatment of mallet finger was surgical and was reported by Mason in 1930 [13,14] and then by Pratt in 1957 [7]. The conservative treatment was described by Smilie in 1936 [12], and reflected advancements in physiopathology and to the use of plaster of Paris splints to immobilize the distal interphalangeal joint (DIPJ) in extension and the proximal interphalangeal joint (PIPJ) in flexion. In 1962, Stack splints, which leave the PIPJ free, entered into use. They are still very frequently used despite the efforts of researchers to propose improved splints. Abouna's splint, described in 1968, is an example of this dynamic. It was rapidly abandoned due to the rusting of its metal wires [4] and of wear of the elastic tensor bands [7]. Following the first clinical series published in the 1960s, Crawford [15] described a method of evaluating therapeutic results in four stages in 1984. Since 1984, a number of surgical and conservative treatments have been described.

\section{Epidemiology}

Mallet finger lesions are common, with a prevalence of $9.3 \%$ of all tendon and ligament lesions in the body and an incidence of $5.6 \%$ of all tendinous lesions in the hand and wrist [16]. Globally, no gender difference is present in the affected population, although high-energy mechanisms of injury are more common in young males and low-energy mechanisms of injury are common in elderly females [17]. All authors concur that the index and thumb fingers are the least frequently affected. However, some researchers have described the middle finger as the most affected [18], whereas others have identified the ring finger to be the most affected [19], and still others the little finger [20]. The dominant hand is more often affected $[18,20]$. Tendinous mallet finger is more common than bony mallet finger [21]. Some authors have proposed that a family predisposition may contribute to mallet finger [6].

\section{Mechanism of injury}

Although specific biomechanical studies have not elucidated the mechanism of injury in mallet finger, several theories have

\section{Fig. 1. Main theories explaining the mechanism of injury}

In all analyses, an axial force is applied to the tip of a straight digit (black arrows), followed by extreme passive distal interphalangeal joint (DIPJ) hyperextension (white upper arrow), which would account for bony lesions, or extreme passive DIPJ hyperflexion (lower white arrow), which would account for tendinous lesions.

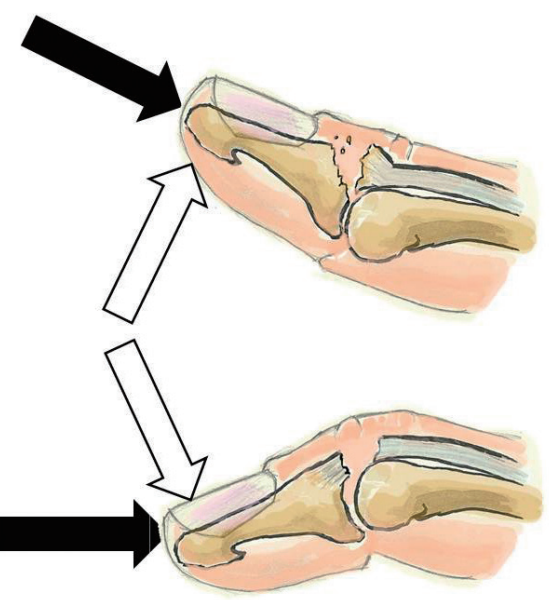

been proposed (Fig. 1). The process is divided into two steps by all researchers. The first step is the application of an axial force to the distal end of a straight finger. The second step varies among authors. Some have argued that the axial force is followed by extreme passive DIPJ hyperextension. This explains bony mallet injuries $[6,22]$. Others have proposed that the axial force is followed by extreme passive DIPJ hyperflexion, which explains tendinous mallet fingers [23]. Other researchers have suggested that the resistance of the oblique retinacular ligament fibers determines tendon or bone avulsion [24]. None of these theories have been proven. The amount of energy involved depends on the patient's age. In younger individuals, mallet finger is most often the result of a high-energy mechanism during sports, involving the impact of a ball onto the hand [6,7]. Multiple-digit injuries have been described [25]. In elderly patients, the mechanism of injury is more often a low energy sedentary activity. Examples include injuries sustained while making a bed [19] or putting socks on $[7,26]$. In children it is more often a direct shock with a crushing mechanism in a door [23].

\section{DIAGNOSIS}

\section{Positive diagnosis}

The diagnosis of mallet finger is essentially clinical. The patient's recent history usually includes the likely mechanism of injury. The patient typically presents in an emergency setting or seeks care later, sometimes several weeks after the injury. The patient usually complains of pain and of being unable to perform full 
active extension of the DIPJ. Upon examination, a passively reducible mallet deformity, swelling, and/or ecchymosis of the dorsal aspect of the DIPJ is found. Pressure is painful [26].

A systematic radiographic lateral and anteroposterior study of the DIPJ looks for a bony articular fragment, an injury to the growth plate, or a subluxed DIPJ [11]. Wehbe and Schneider [10] described a method to measure the size and displacement of the bony fragment (Fig. 2) [2]. Other authors have proposed using ultrasound [27] or magnetic resonance imaging [28] for additional studies, but there is no reason to do so, since clinical examination and standard radiographs are sufficient to establish a diagnosis.

No consensus exists regarding the measurement of passive ex-

\section{Fig. 2. Size and displacement calculation on lateral view}

Ratio of the fractured articular surface over the total articular surface of the distal phalanx base: $T=B / A+B=$ size of fragment in $\%$. The ratio of the gap between the distal phalanx and the bony fragment over the total articular surface of the distal phalanx base: $D=C / A+B=$ fragment displacement in $\%$.

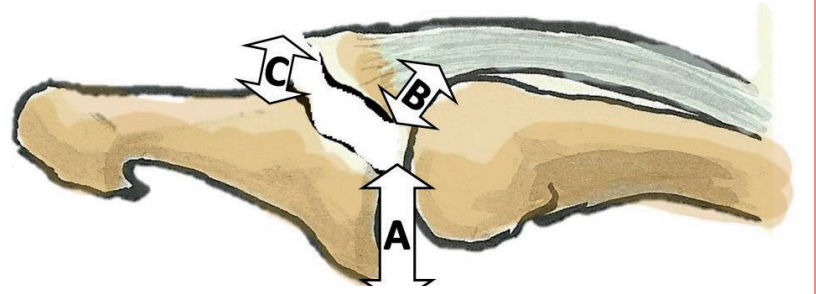

tension deficit in the DIPJ. A clinical method and a radiological method are used. Some researchers have reported using a goniometer without indicating whether they measured the dorsum or the lateral side of the DIPJ [29]. Others have measured lateral $\mathrm{X}$-ray findings, arguing that dorsal swelling overestimates the extension deficit measured clinically [13]. Given the lack of intraobserver and interobserver comparative studies of clinical and radiological measuring methods, we prefer to use the clinical method, which does not increase the number of films taken. We measure the deficit with a goniometer placed on the dorsum of the DIPJ because measurements on the lateral aspect are less predictable.

\section{Differential diagnosis}

Although some authors have considered such injuries to fall into the category of mallet finger, open wounds of the extensor tendon, Seymour lesions, and fractures of more than one third of the distal phalanx joint surface cannot be considered mallet finger.

Swan-neck deformities are due to DIPJ injuries (zone 1 rupture of the extensor tendon), PIPJ injuries (avulsion or distension of the volar plate), or metacarpophalangeal injuries (joint dislocation or intrinsic muscle spasticity). Chronic mallet finger (DIPJ injury) can lead to a swan-neck deformity. A swan-neck deformity in rheumatoid arthritis (PIPJ and/or DIPJ lesion) automatically causes a mallet deformity.

Other lesions involving a deficit of DIPJ passive extension should be differentiated from mallet finger. For example, a Kirner defor-

\section{Fig. 3. Wehbé and Schneider classification}

Type I, no volar subluxation; type II, volar subluxation; type III, growth plate fracture; subtype A, fragment size $<1 / 3$ of the articular surface; subtype $B$, fragment size between $1 / 3$ and $2 / 3$ of the articular surface; sub-type $C$, fragment size $>2 / 3$ of the articular surface.

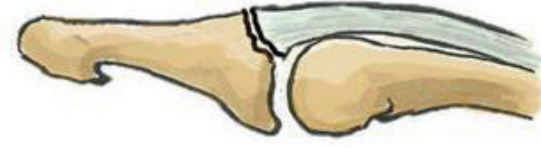

IA

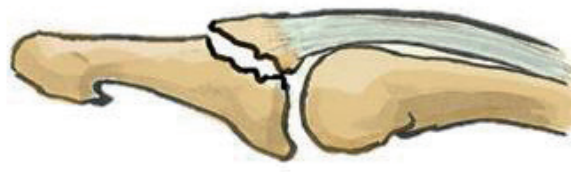

IB

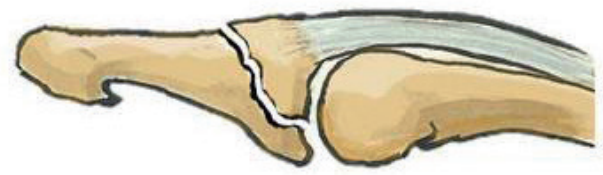

IC

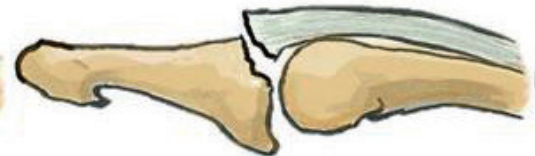

IIA

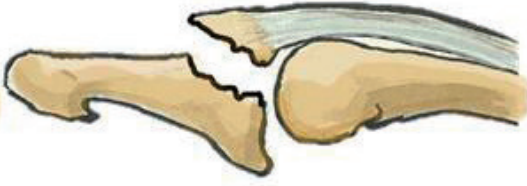

IIB

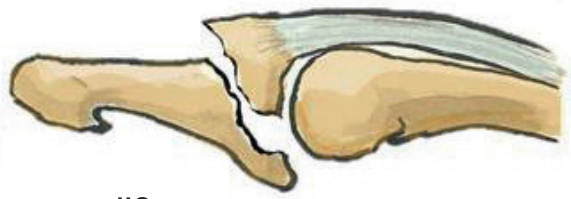

IIC

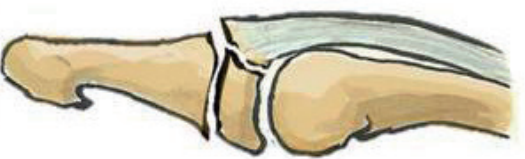

IIIA

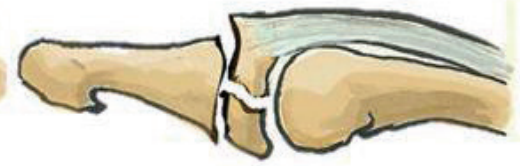

IIIB

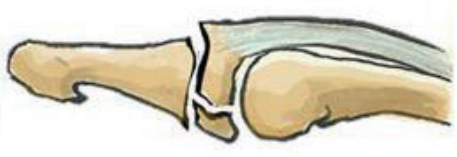

IIIC 
mity is a congenital anomaly of the distal phalanx growth plate that is diagnosed through X-ray imaging [30]. The sequelae of distal phalanx growth plate fractures are further similar lesions [23]. Osteoarthritis and chronic arthropathy arise in different settings.

\section{Classification}

The three classifications of mallet finger are old and were presented by Wehbe in 1984, Tubiana in 1986, and Doyle in 1993. They are all based on radiological assessments. None of these classifications corresponds to a consensus regarding the treatment algorithm, and all include growth plate fracture. The concept of mallet finger developed in this article is not adequately represented by any of these classifications, and we therefore propose a modification of Tubiana's classification.

Wehbe and Schneider's classification [10] describes nine different possible lesions (Fig. 3). It considers the anatomical lesion and the size of the fractured bone fragment, excluding tendinous mallet deformities and open lesions. It does not correlate bone fragment size with volar subluxation. Lesions are subcategorized according to the presence of a bony fragment larger than one third of the articular surface.

Tubiana's classification [12] describes four types of lesions (Fig. 4). It considers the size of the bony fragment and subluxation. It includes tendinous mallet deformities and excludes open

\section{Fig. 4. Tubiana classification}

Type I, subcutaneous tendon rupture; type II, bony avulsion at the base of the distal phalanx; type III, fracture $>1 / 3$ of the articular surface with volar subluxation; type IV, growth plate fracture.

I

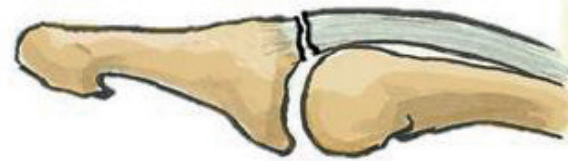

II

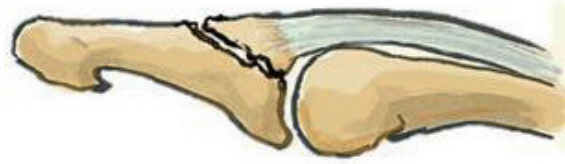

III

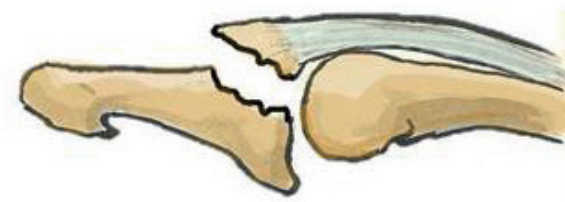

IV

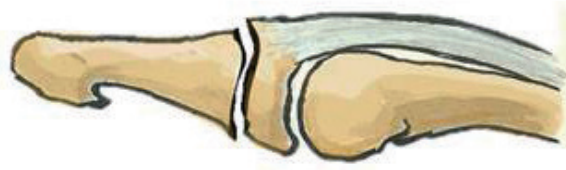

lesions, and correlates bone fragment size with volar subluxation. Lesions are subcategorized according to the presence of a bony fragment larger than one third of the articular surface.

Doyle's classification [8] describes six types of lesions (Fig. 5). It considers the anatomical lesion and the size of the fractured bone fragment, and includes tendinous mallet deformities and open lesions. It does not correlate bone fragment size with volar subluxation. The sizes of the bony fragment that determine the subtype are $20 \%$ and $50 \%$ of the articular surface.

The bone fragment sizes of $1 / 3,20 \%$, or $50 \%$ of the articular surface are arbitrary and do not correspond to any pathophysiological data. Some authors have shown that dorsal fractures of the distal phalanx base become unstable if more than $48 \%$ of the joint surface is avulsed [31]. However, clinical experience shows that subluxation can occur even in smaller avulsions. The per-

\section{Fig. 5. Doyle classification}

Type I, closed mallet finger; type II, open mallet finger; type III, open mallet finger with loss of substance; type IV, bony mallet finger; subtype $A$, involves the growth plate; subtype $B$, fragment size between $20 \%$ and $50 \%$ of the articular surface; subtype $C_{\text {, fragment }}$ size greater than $50 \%$ of the articular surface.

I

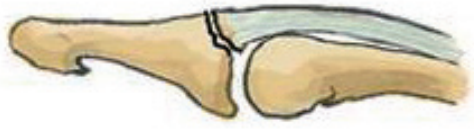

II

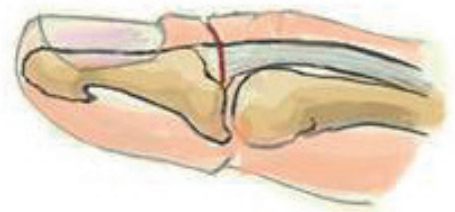

III

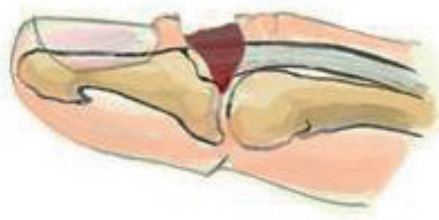

IVA

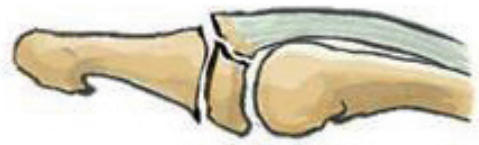

IVB

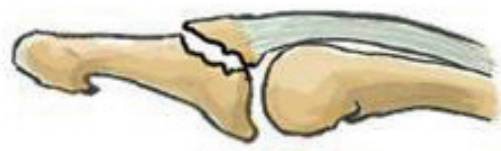

IVC

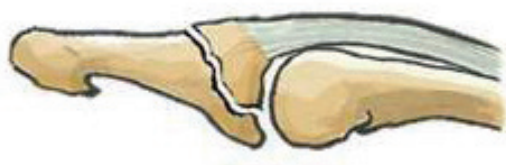


centage of the joint surface involved is therefore not the only factor involved in instability. Concomitant DIPJ volar plate lesions probably play a role in joint instability. Given the current state of our knowledge, it is impossible to establish a classification that accounts for all factors contributing to instability. We propose modifying the Tubiana classification by basing it essentially on DIPJ instability (subluxation) without taking the bone fragment size into consideration (Fig. 6). We have divided the Tubiana stage III into stage III if the subluxation is reduced by a splint and stage IV if the subluxation is not reduced with a splint.

\section{Natural history}

Tendinous mallet finger injuries heal in several phases [32]. During the first 24 hours, an inflammatory response occurs, with neutrophil white cells penetrating the site of injury, which are then followed in the next 24 hours by monocytes and macrophage cells that phagocytates necrotic tissue. Vasoactive and chemotactic factors increase vascular permeability and initiate angiogenesis, tenocyte proliferation, and the synthesis of collagen type III. During the remodeling phase, collagen synthesis peaks during several weeks with high concentrations of glycosaminoglycan and a progressive decrease in cellular content. During this period, the scar tissue is remodeled in two successive phases: consolidation followed by maturation. Consolidation starts at six weeks and continues up to 10 weeks after the injury.

\section{Fig. 6. Modified Tubiana classification}

Type I, subcutaneous tendon rupture; type II, bony avulsion at the base of the distal phalanx; type III, fracture $>1 / 3$ of the articular surface with volar subluxation reducible with a dorsal splint; type $\mathrm{IV}$, fracture $>1 / 3$ of the articular surface with volar subluxation irreducible with a splint.

।

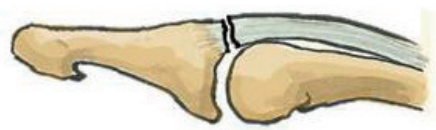

II

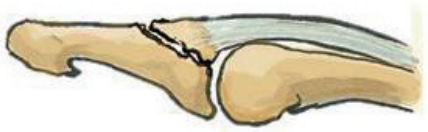

III

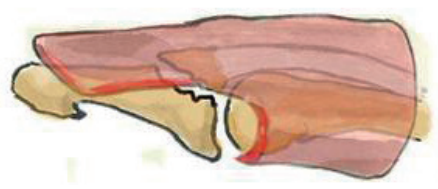

IV

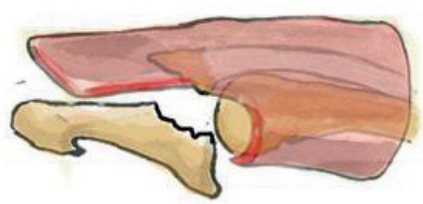

The cellular tissue becomes fibrous. Type III collagens transform into collagen type I. Maturation starts at the tenth week and continues for up to a year after the injury. Tenocyte metabolism and tendon vascularization decrease until a scarred tendon is formed.

The extensor tendon in zone I is extrasynovial, made out of longitudinal fibers that are difficult to securely suture. The terminal band is located directly underneath the skin, and periosteal and tendon-to-skin adhesions therefore frequently occur during the healing process [33]. If the tendon callus is loaded prematurely and too actively, it might lengthen and lead to a fixed mallet deformity. The tendon recovers sufficient resistance to active mobilization in the fifth week of immobilization [34]. This phenomenon accounts for better results after the prolonged use of a night splint [35].

Bony mallet injuries likewise heal in several phases [36]. The inflammatory phase occurs during the first two weeks. Platelet activation releases many components, including fibronectin, platelet-derived growth factor, and transforming growth factor. This process triggers the influx of inflammatory and repair cells (fibroblasts, endothelial cells, and osteoblasts) into the fracture site, contributing to the production of collagen type III. A proliferation phase or formation of a cartilage callus occurs during the third and fourth week. A bridging callus is formed and angiogenesis occurs. The maturation phase or formation of a bone callus occurs during the fifth to the eighth week. Trabecular bone is produced from mesenchymal cells or from a transitional cartilage stage, and both contribute to collagen type I production. Osteoblasts produce trabecular woven bone (randomly oriented fibers) rapidly. Clinical consolidation is complete at this stage. Remodeling starts at the twelfth week and contributes to the production of collagen type I and then collagen type X. The combined actions of osteoclast bone resorption and osteoblast bone formation remodel the bone into a solid lamellar structure.

A bony mallet injury always involves an incomplete tendon avulsion. Part of the distal end of the tendon remains attached to the dorsal DIPJ capsule, which accounts for the more rapid healing of these injuries in comparison to cases of tendinous mallet finger. A persistent periosteal continuity favors bone callus formation [37].

Without treatment, acute mallet finger becomes a chronic deformity. Some authors have used a four-week threshold to define chronic mallet finger [6]; others have placed the threshold at five weeks when surgical treatment is no longer effective [38]. Others have proposed that conservative treatment for acute mallet finger can be undertaken up to two months after the injury [21]. In fact, all mallet finger deformities that do not respond to the conventional treatment of acute mallet finger can be consid- 
ered chronic. Chronic mallet finger can develop esthetic and/or functional complications. In particular, DIPJ extension deficits and swan-neck deformities may be badly tolerated [6]. A bony mallet injury can lead to functionally impairing DIPJ osteoarthritis [6].

\section{TREATMENT}

The objective of treating acute mallet finger is to restore active DIPJ extension. This requires restoring the length of the extensor tendon and obtaining an appropriate healing response. Many conservative and surgical techniques have been described.

\section{Methods}

Conservative treatments vary regarding the immobilization position, type of splint, and treatment duration (Fig. 7).

Since biomechanical studies have demonstrated that PIPJ mobilization does not move the terminal extensor band, researchers no longer recommend PIPJ immobilization in the treatment of mallet finger [39].

The DIPJ immobilization position varies among different authors. Some have advocated hyperextension [40] and others a straight immobilization $[12,41]$. Hyperextension aims at bringing both tendon ends into contact to avoid healing with a lengthened callus. Ischemic skin lesions [4] or, in bony mallet fingers, DIPJ subluxation can occur if DIPJ hyperextension is excessive [42]. We advise moderate hyperextension immobilization for tendinous mallet injuries and straight immobilization for bony mallet injuries [21].

Numerous immobilization devices have been described, with a volar bearing [43], a dorsal bearing [44], or a combined dorsal and volar bearing [41]. The drawbacks of a volar bearing are insufficient DIPJ hyperextension and pulp occlusion that is not

\section{Fig. 7. Different splint types}

From left to right: volar splint, stack splint, and dorsal glued splint.
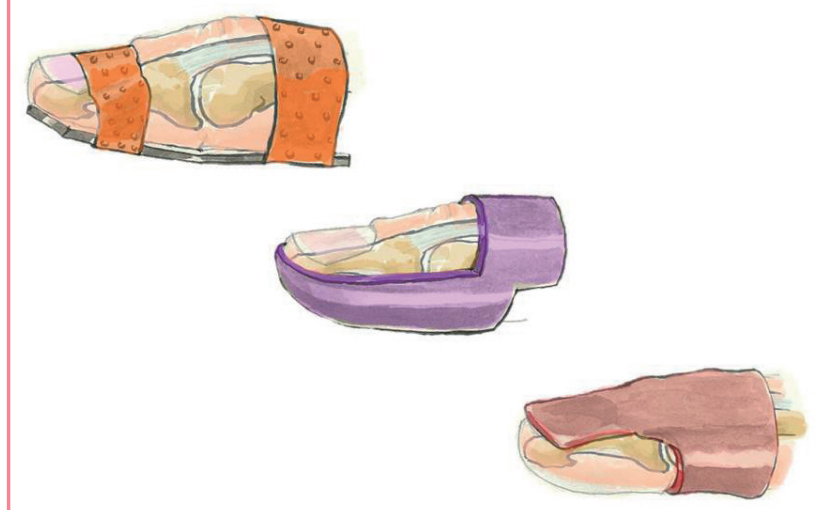

usable during treatment. The main drawback of a dorsal or combined bearing is pressure on the tendon healing site with correspondingly elevated risks of skin maceration and nail dystrophy. In order to counter these complications, some authors have proposed a volar bearing on the middle phalanx combined with a glued dorsal splint on the nail to avoid pressure on the tendon healing site [21]. Custom-made splints yield better results than off-the-shelf splints [29].

A consensus exists that immobilization for a tendinous mallet finger injury should last longer than for a bony mallet injury because tendon healing takes longer than bone healing. For bony mallet finger, treatment lasts between six and eight weeks, but most studies have recommended six weeks $[14,43]$. For tendinous mallet finger, treatment lasts between six and eight weeks, but most studies have recommended eight weeks [43]. After an initial phase of strict immobilization, many authors have proposed continuing treatment with a night splint for two to four weeks $[4,29]$. A level I study has proven, however, wearing a night splint does not affect the outcome of treatment [29].

Poor patient compliance is the main drawback of conservative treatments [35]. Despite explanations regarding the necessity of strictly wearing a splint for a prolonged period of time, some patients remove or reposition the splint or give up the treatment altogether. Patient cooperation is mandatory for obtaining good results. Some authors have described using a glued splint to address the issue of poor compliance [21].

Surgical treatments vary regarding the approach, principle of reduction, and fixation equipment. The surgical approach can be open or percutaneous. An open approach has the advantage of providing direct access to the extensor tendon. The risks are skin necrosis, infection, nail dystrophy, osteoarthritis, and stiffness [7]. These risks are reduced in a percutaneous approach, but this technique presents the risk of imperfect bone reduction.

Reduction and fixation of the displaced fragment can performed directly and/or indirectly. Direct methods include the transosseous suture of a tendinous mallet or of a small bony fragment [45], as well as fixation of a large bony fragment with a variety of hardware, such as K-wires [38,46-49], screws [50], needles [51], external fixators [52], tension wires [53], and plates [54,55]. Indirect methods involve reducing and fixing the displaced bone without going through the osteotendinous lesion. The main techniques are transarticular DIPJ pinning and the Ishiguro method (Fig. 8) [37]. The main drawbacks of these techniques are shortterm stiffness and septic arthritis and long-term osteoarthritis. Some authors combine these techniques by performing a transosseous suture protected by a transarticular DIPJ wire and/or a splint until the hardware is removed $[38,46]$. 


\section{Fig. 8. Ishiguro technique}

We use it in type IV lesions according to the modified Tubiana classification (A). Under fluoroscopy the distal interphalangeal joint (DIPJ) is flexed (B), and a first $\mathrm{K}$-wire is pinned through the extensor tendon into the middle phalanx. The wire is used as a lever that pushes on the bony fragment once the DIPJ is extended (C). A second $\mathrm{K}$-wire is put across the DIPJ to avoid flexion (D).
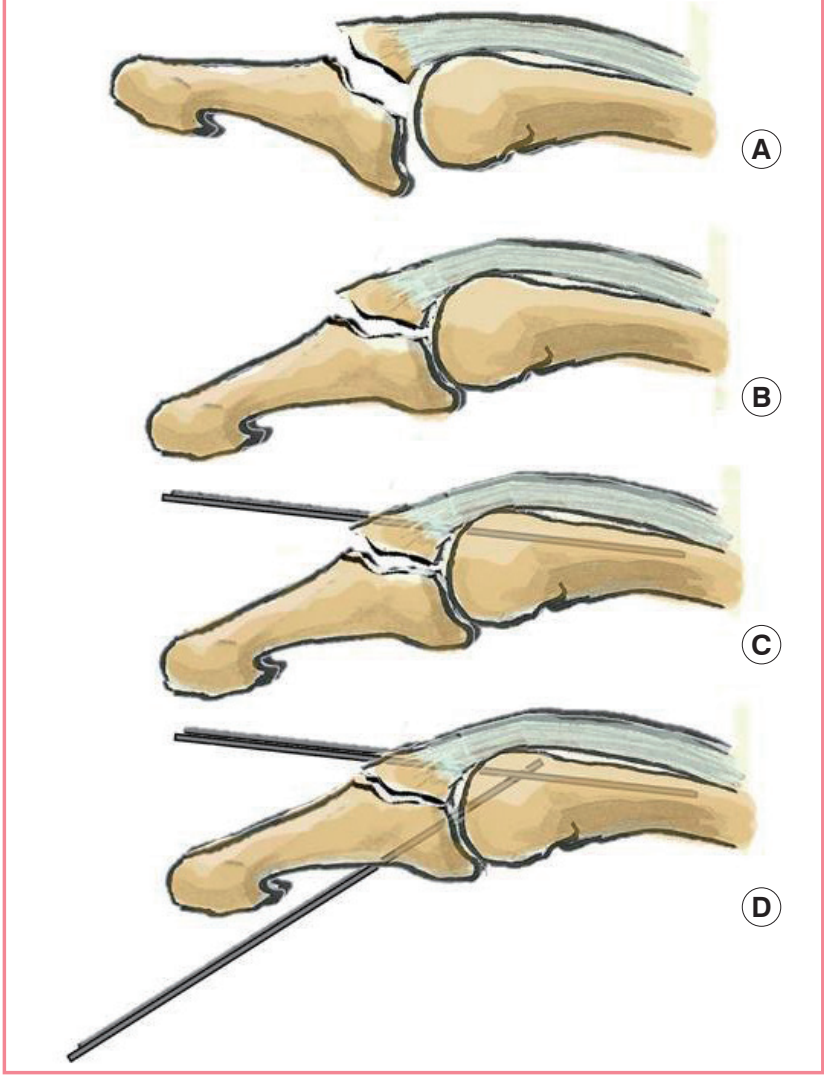

\section{Indications and contraindications}

Most authors agree regarding the indications for the treatment of closed mallet finger lesions in adults, but advocate a variety of treatment techniques. The classification of the lesion is the most important deciding factor. Patient history (including compliance and occupation), the time elapsed since the initial trauma, and the degree of the extension deficit also enter into consideration.

No therapeutic consensus exists. In the literature, specific indications are described, but no decision algorithm is given. For example, some authors have proposed that health professionals should always undergo surgical treatment in order to minimize time off the job [56,57], while others have suggested that wearing a glued splint on the nail leaves the pulp free to be used, enabling the patient to continue working [21]. Most authors have described treating tendinous mallet fingers conservatively, except for one researcher who reported treating them surgically with a direct suture and transarticular DIPJ pinning [45]. Some only consider the amount of fractured articular surface without

\section{Fig. 9. Extra-articular fixed pinning}

An intramedullary 1.2-mm K-wire is put through the distal phalanx percutaneously. A second threaded wire is introduced perpendicularly to the long axis of the middle phalanx from a dorsal approach and abuts the volar cortex to respect the flexor tendon. Both wires are bent and fixed together with two connectors.
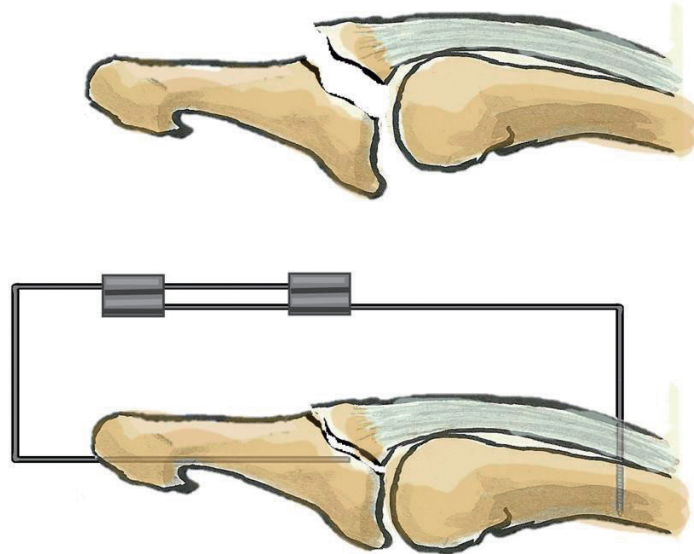

considering the presence of DIPJ subluxation when offering surgical treatment. The threshold varies among authors, ranging from above one third $[38,46]$ to above $48 \%$ [31] or above two thirds [10] of the articular surface. Others have taken into account the presence of irreducible subluxation despite proper splinting, not considering the fractured articular surface when offering surgical treatment $[21,58]$. Some authors have argued that no indications for surgical treatment exist [7].

Given this lack of consensus, we propose a decision algorithm based on a simple modification of Tubiana's classification. All mallet fingers should be treated conservatively with a dorsal glued splint except for type IV lesions. A type IV lesion is a type III lesion with volar subluxation that is not reduced despite a dorsal glued splint. No surgical technique has been proven superior in treating this condition. Nonetheless, we propose the use of extra-articular fixed pinning (Fig. 9) [59].

Factors making patient compliance extremely unlikely (e.g., Alzheimer disease, dementia, or major psychiatric disorders) is a relative contraindication for conservative treatment.

\section{Results}

No consensus exists for evaluating the results of treatment. At least three methods of evaluation have been proposed in the literature. None take age into account, although some have argued that age is directly proportional to the DIPJ residual extension deficit $[4,29]$. The Crawford clinical classification involves four clinical presentations based on two factors: the active extension deficit measured in degrees and pain or the lack thereof [15]. 
Table 1. Acute mallet finger main series results

\begin{tabular}{|c|c|c|c|c|c|c|c|}
\hline \multirow[b]{2}{*}{ Author } & \multirow[b]{2}{*}{ Year } & \multirow[b]{2}{*}{$\begin{array}{l}\text { Level of } \\
\text { evidence } \\
(I-V)\end{array}$} & \multirow[b]{2}{*}{ Case (n) } & \multirow[b]{2}{*}{ Treatment } & \multicolumn{3}{|c|}{ Results } \\
\hline & & & & & $\begin{array}{c}\text { Crawford EGFP } \\
(\%)\end{array}$ & $\begin{array}{c}\text { DIP } \\
\text { extension } \\
\text { deficit }\left({ }^{\circ}\right)\end{array}$ & Complications \\
\hline Stark et al. [9] & 1987 & - & 36 & Trans DIP K-wire+ORIF with K-wire & - & 2 & 0 \\
\hline Bauze and Bain [62] & 1999 & - & 10 & Suture+ORIF with K-wire & - & 5 & $\begin{array}{l}2 \text { Nail deformities, } 1 \text { superficial } \\
\text { infection, } 1 \text { pin track infection }\end{array}$ \\
\hline Takami et al. [63] & 2000 & - & 33 & Trans DIP K-wire+ORIF with K-wire & - & 4 & $\begin{array}{l}6 \text { Slight osteoarthritis, } 1 \text { bone } \\
\text { fragmentation }\end{array}$ \\
\hline Tetik and Gudemez [47] & 2002 & - & 17 & Extension block modified & $\mathrm{E} 17$ & 1,6 & 0 \\
\hline Pegoli et al. [49] & 2003 & - & 69 & Ishiguro & E30, G21, F13, P1 & & $\begin{array}{l}1 \text { Pin tract infection, } 2 \text { nail } \\
\text { deformities }\end{array}$ \\
\hline Kronlage and Faust [3] & 2004 & - & 12 & Screw fixation & - & 6 & $\begin{array}{l}\text { 1 Screw prominence, } 1 \text { non } \\
\text { compliance }\end{array}$ \\
\hline Badia et al. [1] & 2004 & - & 16 & K-wire fixation extension block & - & 2 & 0 \\
\hline Rocchi et al. [48] & 2006 & - & 48 & $\begin{array}{l}\text { K-wire percutaneous «umbrella handle» } \\
\text { like }\end{array}$ & $\mathrm{E} 11, \mathrm{G} 35, \mathrm{~F} 2$ & 5,1 & 1 Pin tract infection \\
\hline Teoh and Lee [54] & 2007 & - & 9 & Hook plate fixation & E4, G5 & 0 & $\begin{array}{l}\text { Dorsal soft-tissue swelling over } \\
\text { the dip joint }\end{array}$ \\
\hline Lee et al. [46] & 2009 & - & 32 & $\begin{array}{l}\text { K-wire percutaneous (double dorsal } \\
\text { K-wires) }\end{array}$ & E69, G25, F6 & 0,9 & $\begin{array}{l}1 \text { Superficial infection, } 2 \text { Nail } \\
\text { deformities, } 3 \text { nail ridgings }\end{array}$ \\
\hline Zhang et al. [64] & 2010 & - & 65 & Trans DIP K-wire+pull out & $\mathrm{E} 52, \mathrm{G} 8, \mathrm{~F} 4, \mathrm{P} 1$ & 7 & 1 Pain \\
\hline Phadnis et al. [65] & 2010 & - & 20 & Trans DIP K-wire+ORIF with K-wire & $\mathrm{E} 6, \mathrm{G} 10, \mathrm{~F} 3, \mathrm{P} 1$ & 1,25 & 1 Infection \\
\hline O'Brien and Bailey [42] & 2011 & $\|$ & 64 & Splint & $\mathrm{E} 64, \mathrm{G} 18, \mathrm{~F} 16, \mathrm{P} 2$ & 4,4 & $\begin{array}{l}\text { 23.8\% (inflammation, pain, } \\
\text { superficial infection) }\end{array}$ \\
\hline Tung et al. [66] & 2012 & - & 13 & Tenodesis & E7, G5 & & 0 \\
\hline Chung and Lee [38] & 2012 & - & 14 & Trans DIP K-wire+percutaneous K-wire & E9, G5 & 1,8 & 1 Pin track infection \\
\hline Kang and Lee [67] & 2012 & - & 16 & Trans DIP K-wire+ORIF with K-wire & $\mathrm{E} 11, \mathrm{G} 3, \mathrm{~F} 2$ & 2,5 & $\begin{array}{l}3 \text { Nail deformity, } 1 \text { flexion loss } \\
5^{\circ}\end{array}$ \\
\hline Tocco et al. [68] & 2013 & I & 57 & Splint+cast & - & 5 & $31.2 \%$ Swan neck \\
\hline Lu et al. [45] & 2013 & IV & 10 & Trans DIP K-wire+pull-in suture & E2, G7, F1 & 0 & 0 \\
\hline Miura [52] & 2013 & - & 12 & K-wire+mini-external fixator & E10, G2 & 2 & 0 \\
\hline Kakinoki et al. [53] & 2013 & - & 13 & Tension band fixation & - & 0 & 1 Osteophyte, 1 joint stiffness \\
\hline Devan [40] & 2014 & IV & 15 & Splint+elastic tape & - & 1,9 & $11 \%$ \\
\hline Shimura et al. [50] & 2014 & - & 20 & Percutaneous screw fixation & E7, G9, F4 & 6,5 & 1 Dorsal ridging, 1 nail bump \\
\hline Miranda et al. [51] & 2015 & - & 12 & Blunt needle reduction & - & 4,6 & 1 Nail bump, 1 displacement \\
\hline Acar et al. [55] & 2015 & IV & 19 & Ishiguro \& hook plate & E10, G9 & 3,9 & $\begin{array}{l}\text { 5.2\% Nail deformity, } 10.4 \% \\
\text { dorsal prominence }\end{array}$ \\
\hline
\end{tabular}

The result is considered excellent if the extension deficit is between $0^{\circ}$ and $10^{\circ}$, good if it is between $10^{\circ}$ and $25^{\circ}$, average if it is greater than $25^{\circ}$ and poor if it is painful. The Bischoff classification includes three radiological stages based on the interfragmentary gap and the intra-articular step [60]. The result is excellent if there is no gap and no step, satisfactory if the gap is less than $2 \mathrm{~mm}$ and/or the step is less than $1 \mathrm{~mm}$ with bony consolidation, and poor if no bony consolidation or joint subluxation is present. The schema presented by Warren et al. [4] and Abouna and Brown [61] comprises three clinical stages based on the active and passive extension deficit measured in degrees. The result is considered excellent if the active extension deficit is between $0^{\circ}$ and $5^{\circ}$, average if it is between $5^{\circ}$ and $15^{\circ}$, and poor if it is greater than $15^{\circ}$. Although some authors have shown that no correlation exists between the residual DIPJ extension deficit and patient satisfaction [29], the Crawford clinical classification seems the most relevant because no direct correspondence has been shown between the final radiological outcomes and the clinical results.

The current consensus based on a Cochrane meta-analysis is first-intention conservative treatment [7]. The main studies are presented in Table 1. Most studies have shown no difference between conservative and surgical treatment, with their authors advocating conservative treatment $[44,69]$. The only comparative study of surgical versus conservative treatment showed no statistically significant difference and recommended a conservative treatment strategy due to the potential complications of surgical treatment [70]. All studies comparing conservative treatments recommend the use of a thermoplastic splint, but no consensus exists whether to use a dorsal or volar splint $[13,42,61,68]$. 
Among the studies of surgical treatment techniques, only one compared the Ishiguro method to fixation with a hook plate. The outcomes were not significantly different, but the hook plate was found to increase the surgical time, decrease the use of fluoroscopy, hasten consolidation by a week, and shorten the delay before returning to work [56]. Many surgical studies have been published, but none are above level IV of evidence.

The complications of conservative treatment are frequent (45\%) and most often are benign and temporary. Skin lesions, including maceration, ulcers, superficial infections, and nail dystrophy, are especially common [20]. Swan-neck deformity is rare but much more impairing. The complication rate of surgical treatment has been reported to range from $3 \%$ to $53 \%[20,54]$. These complications are less frequent but are often serious, including: infection associated with a wire, osteoarthritis, stiffness, nail dystrophy, and skin necrosis $[7,38]$.

\section{CONCLUSIONS}

Closed acute mallet finger lesions, either tendinous or bony, are frequent in adults. No evidence indicates that surgical treatment is superior except in cases of irreducible volar DIPJ subluxation despite the proper use of a splint. Treatment is mandatory to avoid chronic lesions.

\section{REFERENCES}

1. Badia A, Riano F. A simple fixation method for unstable bony mallet finger. J Hand Surg Am 2004;29:1051-5.

2. Bendre AA, Hartigan BJ, Kalainov DM. Mallet finger. J Am Acad Orthop Surg 2005; 13:336-44.

3. Kronlage SC, Faust D. Open reduction and screw fixation of mallet fractures. J Hand Surg Br 2004;29:135-8.

4. Abouna JM, Brown $H$. The treatment of mallet finger: the results in a series of 148 consecutive cases and a review of the literature. Br J Surg 1968;55:653-67.

5. Alla SR, Deal ND, Dempsey IJ. Current concepts: mallet finger. Hand (N Y) 2014;9:138-44.

6. Moss JG, Steingold RF. The long term results of mallet finger injury: a retrospective study of one hundred cases. Hand 1983;15:151-4.

7. Handoll HH, Vaghela MV. Interventions for treating mallet finger injuries. Cochrane Database Syst Rev 2004;(3):CD 004574.

8. Doyle JR. Extensor tendons acute injuries. In: Green DP, editor. Operative hand surgery. 3rd ed. New York: Churchill Livingstone; 1993. p.1950-87.

9. Stark HH, Gainor BJ, Ashworth CR, et al. Operative treat- ment of intra-articular fractures of the dorsal aspect of the distal phalanx of digits. J Bone Joint Surg Am 1987;69:892-6.

10. Wehbe MA, Schneider LH. Mallet fractures. J Bone Joint Surg Am 1984;66:658-69.

11. Nellans KW, Chung KC. Pediatric hand fractures. Hand Clin 2013;29:569-78.

12. Tubiana R. Mallet finger. In: Tubiana R, editor. Traite de chirurgie de la main. Paris; New York: Masson; 1986. p.10921.

13. Pike J, Mulpuri K, Metzger M, et al. Blinded, prospective, randomized clinical trial comparing volar, dorsal, and custom thermoplastic splinting in treatment of acute mallet finger. J Hand Surg Am 2010;35:580-8.

14. Valdes K, Naughton N, Algar L. Conservative treatment of mallet finger: a systematic review. J Hand Ther 2015;28: 237-45.

15. Crawford GP. The molded polythene splint for mallet finger deformities. J Hand Surg Am 1984;9:231-7.

16. de Jong JP, Nguyen JT, Sonnema AJ, et al. The incidence of acute traumatic tendon injuries in the hand and wrist: a 10year population-based study. Clin Orthop Surg 2014;6:196202.

17. Clayton RA, Court-Brown CM. The epidemiology of musculoskeletal tendinous and ligamentous injuries. Injury 2008; 39:1338-44.

18. Stark HH, Boyes JH, Wilson JN. Mallet finger. J Bone Joint Surg Am 1962;44:1061-8.

19. Robb WA. The results of treatment of mallet finger. J Bone Joint Surg Br 1959;41:546-9.

20. Stern PJ, Kastrup JJ. Complications and prognosis of treatment of mallet finger. J Hand Surg Am 1988;13:329-34.

21. Facca S, Nonnenmacher J, Liverneaux P. Treatment of mallet finger with dorsal nail glued splint: retrospective analysis of 270 cases. Rev Chir Orthop Reparatrice Appar Mot 2007; 93:682-9.

22. Lange RH, Engber WD. Hyperextension mallet finger. Orthopedics 1983;6:1426-31.

23. Ganayem M, Edelson G. Base of distal phalanx fracture in children: a mallet finger mimic. J Pediatr Orthop 2005;25: 487-9.

24. Zancolli E. Structural and dynamic bases of hand surgery. Philadelphia: J. B. Lippincott; 1968.

25. Degreef I, De Smet L. Multiple simultaneous mallet fingers in goalkeeper. Hand Surg 2009;14:143-4.

26. Yeh PC, Shin SS. Tendon ruptures: mallet, flexor digitorum profundus. Hand Clin 2012;28:425-30.

27. Kleinbaum Y, Heyman Z, Ganel A, et al. Sonographic imaging of mallet finger. Ultraschall Med 2005;26:223-6. 
28. Clavero JA, Alomar X, Monill JM, et al. MR imaging of ligament and tendon injuries of the fingers. Radiographics 2002; 22:237-56.

29. Gruber JS, Bot AG, Ring D. A prospective randomized controlled trial comparing night splinting with no splinting after treatment of mallet finger. Hand (N Y) 2014;9:145-50.

30. Wang QC, Johnson BA. Fingertip injuries. Am Fam Physician 2001;63:1961-6.

31. Kim JK, Kim DJ. The risk factors associated with subluxation of the distal interphalangeal joint in mallet fracture. J Hand Surg Eur Vol 2015;40:63-7.

32. Sharma P, Maffulli N. Biology of tendon injury: healing, modeling and remodeling. J Musculoskelet Neuronal Interact 2006;6:181-90.

33. Vaienti L, Merle M. Lésions de l’appareil extenseur. In: Merle M, Dautel G, editors. La main traumatique. Paris: Masson; 1997.p.233-50.

34. Mason ML. Rupture of tendons in the hand: with a study of the extensor tendon insertions in the fingers. Surg Gynecol Obst 1930;50:611-62.

35. Pratt DR, Bunnell S, Howard LD Jr. Mallet finger: classification and methods of treatment. Am J Surg 1957;93:573-8.

36. Marsh DR, Li G. The biology of fracture healing: optimising outcome. Br Med Bull 1999;55:856-69.

37. Ishiguro T, Itoh Y, Yabe Y, et al. Extension block with Kirschner wire for fracture dislocation of the distal interphalangeal joint. Tech Hand Up Extrem Surg 1997;1:95-102.

38. Chung DW, Lee JH. Anatomic reduction of mallet fractures using extension block and additional intrafocal pinning techniques. Clin Orthop Surg 2012;4:72-6.

39. Katzman BM, Klein DM, Mesa J, et al. Immobilization of the mallet finger: effects on the extensor tendon.J Hand Surg Br 1999;24:80-4.

40. Devan D. A novel way of treating mallet finger injuries. J Hand Ther 2014;27:325-8.

41. Stack G. Mallet finger. Lancet 1968;2:1303.

42. O’Brien LJ, Bailey MJ. Single blind, prospective, randomized controlled trial comparing dorsal aluminum and custom thermoplastic splints to stack splint for acute mallet finger. Arch Phys Med Rehabil 2011;92:191-8.

43. Smit JM, Beets MR, Zeebregts CJ, et al. Treatment options for mallet finger: a review. Plast Reconstr Surg 2010;126: 1624-9.

44. Hart RG, Kleinert HE, Lyons K. The Kleinert modified dorsal finger splint for mallet finger fracture. Am J Emerg Med 2005;23:145-8.

45. Lu J, Jiang J, Xu L, et al. Modification of the pull-in suture technique for mallet finger. Ann Plast Surg 2013;70:30-3.
46. Lee YH, Kim JY, Chung MS, et al. Two extension block Kirschner wire technique for mallet finger fractures. J Bone Joint Surg Br 2009;91:1478-81.

47. Tetik C, Gudemez E. Modification of the extension block Kirschner wire technique for mallet fractures. Clin Orthop Relat Res 2002;(404):284-90.

48. Rocchi L, Genitiempo M, Fanfani F. Percutaneous fixation of mallet fractures by the "umbrella handle" technique.J Hand Surg Br 2006;31:407-12.

49. Pegoli L, Toh S, Arai K, et al. The Ishiguro extension block technique for the treatment of mallet finger fracture: indications and clinical results. J Hand Surg Br 2003;28:15-7.

50. Shimura H, Wakabayashi Y, Nimura A. A novel closed reduction with extension block and flexion block using Kirschner wires and microscrew fixation for mallet fractures. J Orthop Sci 2014;19:308-12.

51. Miranda BH, Murugesan L, Grobbelaar AO, et al. PBNR: percutaneous blunt needle reduction of bony mallet injuries. Tech Hand Up Extrem Surg 2015;19:81-3.

52. Miura T. Extension block pinning using a small external fixator for mallet finger fractures. J Hand Surg Am 2013;38: 2348-52.

53. Kakinoki R, Ohta S, Noguchi T, et al. A modified tension band wiring technique for treatment of the bony mallet finger. Hand Surg 2013; 18:235-42.

54. Teoh LC, Lee JY. Mallet fractures: a novel approach to internal fixation using a hook plate. J Hand Surg Eur Vol 2007; $32: 24-30$

55. Acar MA, Guzel Y, Gulec A, et al. Clinical comparison of hook plate fixation versus extension block pinning for bony mallet finger: a retrospective comparison study. J Hand Surg Eur Vol 2015;40:832-9.

56. Baratz ME, Schmidt CC, Hugues TB. Extensor tendon injuries. In: Green DP, Wolfe SW, editors. Green's operative hand surgery. 6th ed. Philadelphia: Saunders/Elsevier; 2010. p.187218.

57. Chauhan A, Jacobs B, Andoga A, et al. Extensor tendon injuries in athletes. Sports Med Arthrosc 2014;22:45-55.

58. Reading GR. Discussion of reassessment of surgery of mallet finger. Plastic Reconst Surg 1994;93:150-1.

59. Prunières G, Gouzou S, Facca S, et al. Treatment of unstable distal phalanx fractures by extra-articular DIP pinning: a series of 12 cases. Chir Main. Forthcoming 2016.

60. Bischoff R, Buechler U, De Roche R, et al. Clinical results of tension band fixation of avulsion fractures of the hand.J Hand Surg Am 1994;19:1019-26.

61. Warren RA, Norris SH, Ferguson DG. Mallet finger: a trial of two splints. J Hand Surg Br 1988;13:151-3. 
62. Bauze A, Bain GI. Internal suture for mallet finger fracture. J Hand Surg Br 1999;24:688-92.

63. Takami H, Takahashi S, Ando M. Operative treatment of mallet finger due to intra-articular fracture of the distal phalanx. Arch Orthop Trauma Surg 2000;120:9-13.

64. Zhang X, Meng H, Shao X, et al. Pull-out wire fixation for acute mallet finger fractures with $\mathrm{k}$-wire stabilization of the distal interphalangeal joint.J Hand Surg Am 2010;35:1864-9.

65. Phadnis J, Yousaf S, Little N, et al. Open reduction internal fixation of the unstable mallet fracture. Tech Hand Up Extrem Surg 2010;14:155-9.

66. Tung KY, Tsai MF, Chang SH, et al. Modified tenodesis method for treatment of mallet fractures. Ann Plast Surg 2012;69:622-6.
67. Kang HJ, Lee SK. Open accurate reduction for irreducible mallet fractures through a new pulp traction technique with primary tendon repair.J Plast Surg Hand Surg 2012;46:43843.

68. Tocco S, Boccolari P, Landi A, et al. Effectiveness of cast immobilization in comparison to the gold-standard self-removal orthotic intervention for closed mallet fingers: a randomized clinical trial.J Hand Ther 2013;26:191-200.

69. Bloom JM, Khouri JS, Hammert WC. Current concepts in the evaluation and treatment of mallet finger injury. Plast Reconstr Surg 2013;132:560e-566e.

70. Auchincloss JM. Mallet-finger injuries: a prospective, controlled trial of internal and external splintage. Hand 1982;14: 168-73. 